\title{
The Influence Of Wage On Motivation And Satisfaction
}

\author{
Eder Paschoal Pinto, Universidade Salvador, Laureate International Universities, Brazil
}

\begin{abstract}
This article seeks to contribute to the extant literature on the origin of motivation (intrinsic or extrinsic) by examining the relationship between wage, motivation, and satisfaction. That is, its aims is to discover the extent to which wages influence the motivation and satisfaction of wage earners who are considered to be more highly motivated than their colleagues. Employees who work for eight companies from diverse segments of the Brazilian economy were selected by intentional sampling. The data collection process was carried out along with them by explaining the objectives of the survey and handing out the forms that were to be completed by them. Four hundred fifty-eight useful answers were validated. The results show that the wages paid by the companies do not significantly influence the respondents' motivation and satisfaction, with the exception for a highly limited sample. These constructs (motivation and satisfaction) were investigated in terms of the way the work is organized, the communication is processed, and the rewards system is built. The findings are opposite of those that assert the positive influence of extrinsic rewards (salary is one of them) on motivation. The article offers an original research design; that is, with a focus on highly motivated wage earners. Similar research design is strongly recommended in order to elucidate a little more on the influence of wages on motivation.
\end{abstract}

Keywords: Wage; Motivation; Satisfaction; Extrinsic Rewards

\section{INTRODUCTION}

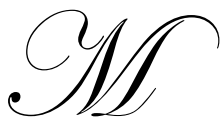

Focusing on distinct profiles of workers may provide findings that would not have been accessed had they not been investigated. It is an alternative or different way to carry out research on motivation; that is, usually researchers invite workers to participate in studies on motivation without considering the existing differences in the motivation profiles. On the other hand, marketing researchers have constantly surveyed consumer profiles to discover their distinctive preferences.

Numerous researchers, including Alfie Kohn (1993), have studied the influence of wages on motivation. Kohn believes that the majority of US corporations use incentive plans to motivate workers. However, he says, "But more striking is the rarely examined belief that people will do a better job if they had been promised some sort of incentives" (p. 2).

From the beginning and up to the middle of the last century, the predominant understanding was that financial compensations had a strong influence on motivation (Thomas, 2009). Since Herzberg (1968) discovered that wages have little influence on motivation, many studies dealing with the subject have been carried out.

Recent findings have presented wages as a motivational factor (extrinsic); that is, they contradict research findings that assert the intrinsic character of motivation. Some examples, in historical order, are: 
- $\quad$ Surveying primary and middle school teachers, Gawel (1997) verified that when the objectives of certain educational plans were associated with financial rewards, the educators put forth more effort in their jobs.

- $\quad$ Examining the ranked importance of motivational factors of employees at Ohio State University, Lindner (1998) verified that within the ten most valued factors, the respondents mentioned wages as \#2.

- In surveying job satisfaction among Russian workers, Linz (2003) found that the possibility of receiving additional pay relates positively with job satisfaction.

- $\quad$ Ohtake and Karato (2005) found that introducing a performance-based wage system, on average, has no significant impact on the motivation to work. However, enhanced motivation to work is observed among white-collar workers, workers with high wage levels, and among those given wage increases.

- $\quad$ Studying the motivation, participation, and performance of open-source software developers, Roberts, IlHorn, and Slaughter (2006) found that when financial rewards are associated with contribution to project development, the developers' motivation status increases.

- $\quad$ Jenica (2007) reported that good wages were at the middle of a list ranked by employees during the period 1980 to 1990, and topped the list in the 1990s and has maintained this position up to the beginning of the 2000s.

Considering the different findings between previous and recent surveys, the following question was asked: "To what extent does the actual wage relate to the motivation and satisfaction of the wage earners considered highly motivated?"

Following the recent findings, it is stated that wage, as an extrinsic phenomenon to the individual, influences her/his motivation; that is, it is assumed that wage (extrinsic factor) may influence a worker's motivation to communication, work organization, and rewards. In mathematical terms: $Y=f(X)$, where $Y$ is motivation (to work organization, communication, and rewards) and $X$ is the wage. In other words, the higher the wage a worker earns, the higher their motivation is expected to be.

At the core of the above assumption is the theoretical chain, which affirms that extrinsic rewards influence a person's behavior (Beer and Nohria, 2000; Eisenberger and Cameron, 1996; and Lawler, 2000). On the other hand, the stated hypothesis is contrary to the theory, which asserts that motivation is an intrinsic phenomenon to the individual. More specifically, researchers who assert the intrinsic character of motivation say that the financial reward, as an extrinsic factor to the individual, does not significantly relate to her/his motivation (Herzberg, 1968). Specifically, the introduction of extrinsic rewards for behavior that is intrinsically rewarding may decrease rather than enhance overall motivation (Deci and Ryan, 1985, and Ryan and Deci, 2000). Additionally, the wage may negatively influence performance if it does not correspond to the applied efforts or if it is unequally paid among workers (Adams, 1965). More emphatically, "punishment and rewards are actually two sides of the same coin. Both have a punitive effect because they are manipulative [...] Incentive does not alter the attitudes that underlie our behaviors" (Kohn, 1993, p. 2).

Considering the different viewpoints expressed by the above-mentioned researchers, this work attempts to contribute to the extant literature describing the relationship between wage, motivation, and satisfaction, focusing on highly motivated wage earners.

The next section presents a brief essay on extrinsic and intrinsic motivation. The subsequent section will present the study's design - more specifically, the population studied, the sampling method, and data gathering instruments, as well as the statistical methods applied to deal with the data. Later, the findings are presented and analyzed, and finally, a conclusion is drawn.

\section{Extrinsic and Intrinsic Motivation and Satisfaction in the Workplace}

It is not easy to define the concept of motivation in a few words. Definitions on motivation generally come from the concept that one holds on the subject, say, for example, the origin of motivation as being intrinsic or extrinsic. 
Those who assert that factors that motive the individual are intrinsic to her/him generally define motivation by including three basics aspects: 1) the internal energy that moves the individual, 2) the direction that the movement takes, and 3) the persistence in such a direction (Greenberg and Baron, 2008; and Latham and Pinder, 2005). In other words, 'motivation is an internal process that defines the intensity, direction, and persistence of the individual seeking his goals.' For those who understand that the motivation of the individual might solely or also emanate from the environment, the offers that are external to the individual have the power to drive her/his behavior (Beer and Nohria, 2000; Lawler, 2000; and Lindner, 1998). For example, Lawler (2000:68) says, “... Unfortunately, critics, such as Deming and the advocates of intrinsic motivation, do not provide viable alternatives to the traditional pay-for-performance approaches; they only provide compelling criticism of them”. Similarly, Beer and Nohria (2000:270) wrote “...specifically, effective compensation systems [...] improve the motivation and productivity of employees..."

According to the authors who understand that motivation is an intrinsic phenomenon, the motivation that is unleashed by external stimuli has a short duration, while that generated by the individual's internal processes has a long duration (Herzberg, 1968; Kohn, 1993). Thus, instead of attempting to "motivate" employees, and in order for the motivation to be energized and sustained in the organizational environment, it is fundamental to understand and satisfy it through factors that may be promoted by the organization (Latham and Pinder, 2005; Lovelock and Wirtz, 2006; Spitzer, 1995, and Thomas, 2009).

According to some authors, things that motivate are an individual's needs, desires and expectations instead of what is offered by the environment. The offer puts into action the target person only if she/he holds the need and wants to satisfy it; that is, if his intellect decides to accept it.

Researchers have discovered that needs, whether psychological or physiological, are embedded in an individual's everyday life (Maslow, 1943) and that the needs' profile changes according to individual targets and achievements (Deci and Ryan, 2000; and McClelland, 1961, 1985), as well as it depends on the interaction of personal goals with organizational objectives (Spitzer, 1995). Furthermore, a person's belief on his/her ability and capacity to accomplish tasks and objectives motivates him/her to constructive actions: the so-called self-efficacy (Bandura, 1982, 1997). In addition, the needs are regarded as essential nutrients for individual subsistence (Ryan, Sheldon, Kasser, and Deci, 1996). Therefore, motivation must be seen as a multi-level phenomenon where individual, group, organizational and cultural variables must be considered to truly understand it (Kanfer, Chen and Pritchard, 2008).

Spitzer (1995) advocates that, through organizational policies and practices, managers may satisfy the needs of their co-workers. On the other hand, the offers extrinsic to the individual may negatively affect the spontaneity of her/his action (Greenberg and Baron, 2008; and Leavitt, Pondy and Boje, 1989). However, opponents of the intrinsic motivation model have criticized those who defend it, such as Beer and Nohria (2000) who say that this group of authors created the "hydraulic motivation model" (p.279). Other authors, such as Thomas (2009), do not see inherent conflict between extrinsic and intrinsic rewards.

Some authors say that work has two aspects - the task and the context (Herzberg, 1968; Schermerhorn, Jr., 2005; and Spitzer, 1995); that is, task is the technical content and the context is everything related to the task.

In order for it to satisfy human desires of activity, property, power, affiliation, competence, achievement, acknowledgement, and meaning (Spitzer, 1995), managers can enrich the work context (Herzberg, 1968, Spitzer, 1995, and Thomas, 2009). Thus, instead of worrying about each employee (due to the difficulty posed with a large number of people) and his task (many tasks are and will continue to be monotonous because of their actual nature), the manager may change the work context in order to attend to collective motivation.

For the organization to become dynamic and energized, Spitzer (1995) proposes to deal with six sets of factors - planning, production, communication, training, evaluation, and rewards.

From previous investigations, it has been concluded that production system (work organization) communication, and rewards might include all the above constructs. Therefore, it is applied only these three in this survey. Some examples of variables are shown in Table 1. 
Table 1: Constructs and Examples of Variables Examined in this Research

\begin{tabular}{|l|l|}
\hline \multicolumn{1}{|c|}{ Construct } & \multicolumn{1}{|c|}{ Examples of Variables } \\
\hline $\begin{array}{l}\text { Work organization system } \\
\text { (production system) }\end{array}$ & $\begin{array}{l}\text { Make a relaxing environment; vary tasks; coach and mentor; respect deadlines and; } \\
\text { commemorate victories, }\end{array}$ \\
\hline Communication system & $\begin{array}{l}\text { Share important information; discuss performance with colleagues; conduct question and } \\
\text { answer sessions; shape the organizational mission, values and vision; encourage people and } \\
\text { give answers to suggestions, and; hold productive meetings. }\end{array}$ \\
\hline Reward system & $\begin{array}{l}\text { Base rewards on competency; enable employee to choose benefits; vary ways of } \\
\text { acknowledgement; be fair with rewards and compensate spontaneous contributions. }\end{array}$ \\
\hline
\end{tabular}

Source: Constructed by the author from Spitzer (1995) recommendations

It is recognized that policies may facilitate the manager's role in relation to theories that propose action for each individual. However, it should be pointed out that different people have different levels of needs and desires at different times (Schermerhorn, 2005). Thus, one understands that in addition to the action on the work context, it is important to identify the profiles of individual motivation at different times.

\section{RESEARCH DESIGN}

Instead of choosing a specific sector (private or public), industry, or some companies from a single region, this study presents responses from companies of different sectors established in two Brazilian regions - the western region of the State of Paraná and the Itajaí's Valley situated in Santa Catarina State. The companies in these regions were chosen by convenience; that is, it was invited several companies of our professional relationship. However, even by convenience, the diversity of the companies established in the two states allows giving answers to the survey problem through supposedly distinct organizational cultures.

Aiming to understand the impact of real wages on most motivated wage earners of the units that present best performance, an intentional sampling process was applied. Firstly, the directors of the invited companies were told about the research aims and motivation concepts in order to provide the conceptual support required to choose the most motivated employees.

The sampling process began by selecting two units in each company who are considered as presenting the best performance. Their directors made the selection; that is, in each company, the directors were asked to identify the two departments she/he considered as having the best performance. The departments that were pointed out most frequently in each company were selected.

Later, the respective managers and directors chose the employees perceived as the most motivated from these departments (50\% most motivated wage earners). The most motivated employees were chosen because they more clearly and intensely reveal the motivation that moves them into action (Spitzer, 1995). That is, they are the ones that perceive, with less difficulty, their needs, desires, and expectations and attempt to satisfy them.

I carried out the data collection process along with the wage earners by explaining the objectives of the survey and handing out the forms that were to be completed by them. One of the forms contains eight questions that aim to identify the respondent's personal profile - mainly the wage the participant earns (independent variable). The second consists of 28 questions to identify the extent of the respondent's motivation to work organization system, communication system, and rewards system. These questions were produced according to Spitzer's proposal - for energizing and sustaining motivation at work - and constructed according to the Likert scale template in which there is a statement and seven levels of application intensity, varying from "This question does not interest me" to "This question interests me completely". The third form also comprises of 28 questions and intends to identify the need satisfaction levels of the respondent. These questions were also produced according to the Likert scale in which there is a statement and seven levels of application intensity, varying from "I have not been able to satisfy this need" to "I have been able to fully satisfy this need." One notes that the basic difference between the second and third forms (both aim to collect the dependent variables) is the use of the terms "interest" in the first one and "need satisfaction" in the second. 
A broad version of questionnaires 2 and 3 was tested in a previous survey; that is, that version had included six factors - planning, production, communication, training, evaluation, and rewards - as recommended by Spitzer (1995). Aiming to reduce the number of variables, the questionnaires were examined by factorial analysis and were condensed into three factors (production, communication, and rewards). Therefore, $79.2 \%$ of the data variance was explained in questionnaire 2, with a KMO indicator of 0.488 , and in questionnaire 3, $77.8 \%$ of the variance was explained and the KMO indicator was 0.50453 .

\section{FINDINGS AND ANALYSIS}

\section{Respondents' Demographic Profile}

The companies that participated in the survey were: (1) State of Paraná: Bank of Brazil (brand of Cascavel), Frimesa S. A. (Factory of Medianeira), Educational College of Medianeira and, Itaipulândia City Hall and (2) State of Santa Catarina: Cremer S. A. (factory of Blumenau), Group Lince (factory of Gaspar), Knitwear Cristina (Factory of Blumenau), and Senior Systems (Unit of Blumenau).

The units selected by the directors of the participant companies were of the following types: nine administrative units, three production units, two bank branches, a higher education school and, a municipal public service. Therefore, the variety of companies, departments and segments (16 departments of eight organizations of diverse economic segments) allowed for verifying the relationship between the surveyed variables in a varied sample.

The demographic profile of the respondents is:

- $\quad 252$ males and 206 females

- 260 married people, 154 single, and 18 divorced

- $\quad 55$ people under the age of 22, 141 from ages 22 to 29, 143 from ages 30 to 39,75 from ages 40 to 49 and 13 aged 50 and older

- $\quad 60$ people had up to three years of professional experience, 83 between 4 and 7 years, 61 between 8 to 11 years, 112 between 12 and 20 years and 106 more than 20 years

- $\quad 381$ people are members of churches and 51 are not

- 293 are Catholics, 63 are Evangelicals or Christian, and 25 follow other denominations

- $\quad 252$ respondents hold a Bachelor's degree; 137 hold a high school certificate, and 40 hold a primary school certificate

One may note that the sums of each demographic variable are different. This happens since certain respondents failed to fill in one or more pieces of information that was requested.

\section{RESULTS}

It was discovered that:

- $\quad$ The actual wages explain $1.2 \%$ of the variance of the set of variables stated in the construct 'motivation for the work organization, with a multiple correlation coefficient of 0.11 and Fischer coefficient of 5.31 (Figure 1).

- $\quad$ The actual wages explain $1.9 \%$ of the variance of the set of variables stated in the construct 'satisfaction with work organization, with a multiple correlation coefficient of 0.14 and Fischer coefficient of 5.31 (Figure 2). 


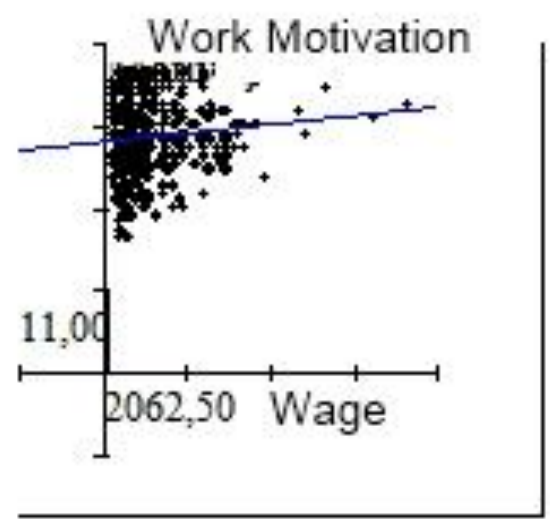

Figure 1: Correlation between Wage and Motivation for the Work Organization

Note: The figure shows the 426 coordinate points: wages; motivation for work. Dependence is not significant. Right regression equation: motivation for work $=0.00 *$ wages +30.93 . Correlation coefficient: +0.11 (wages explains $1.2 \%$ of the work motivation variance). Standard deviation of the regression coefficient: 0.000 . Fisher coefficient: $F=5.31$. 172 observations are not considered (no answer to at least one of the criteria). Each observation is represented by one point.

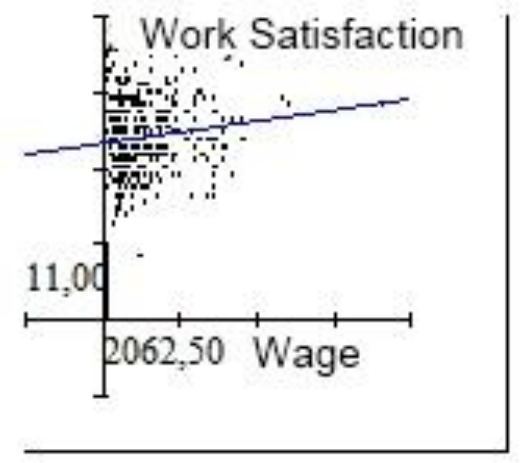

Figure 2: Correlation between Wage and Satisfaction with Work Organization

Note: The figure shows the 426 coordinate points: wages; work satisfaction. Dependence is not significant. Right regression equation: motivation for work $=0.00 *$ wages +26.05 . Correlation coefficient: +0.14 (wages explains $1.9 \%$ of the work satisfaction variance). Standard deviation of the regression coefficient: 0.000 . Fisher coefficient: $F=5.31$.

The other results are expressed in Table 2.

Table 2: Relationship between Actual Wages, Motivation and Satisfaction

\begin{tabular}{|l|c|c|c|}
\hline \multicolumn{1}{|c|}{ Construct } & Variance & $\begin{array}{c}\text { Multiple Correlation } \\
\text { Coefficient }\end{array}$ & Fischer Coefficient \\
\hline Motivation for the communication process & $0.8 \%$ & 0.09 & 3.30 \\
\hline Satisfaction with the communication process & $1.1 \%$ & 0.11 & 4.89 \\
\hline Motivation for rewards & $0.4 \%$ & 0.06 & 1.67 \\
\hline Satisfaction with rewards & $0.6 \%$ & 0.08 & 1.87 \\
\hline
\end{tabular}

Note: Figures 3-6 show detailed results.

Source: Survey conducted by the author. 


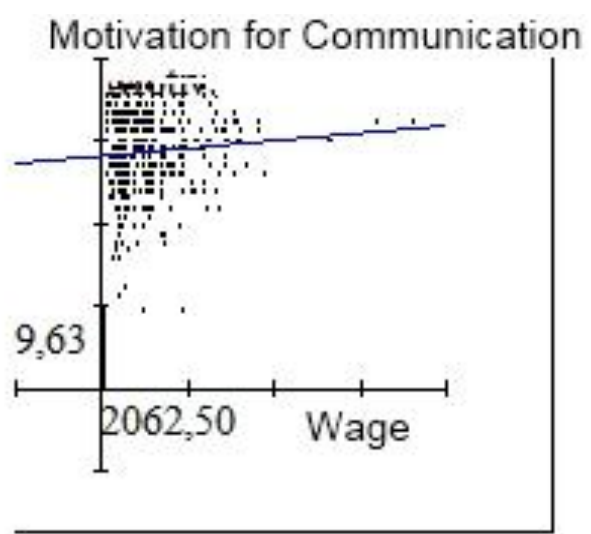

Figure 3: Correlation between Wage and Motivation for the Communication Process

Note: The figure shows the 420 coordinate points: wages; motivation for communication. Dependence is not significant. Right regression equation: motivation for communication $=0.00 *$ wages +27.26 . Correlation coefficient: +0.09 (wages explains $0.8 \%$ of the communication variance). Standard deviation of the regression coefficient: 0.000 . Fisher coefficient: $F=3.30$

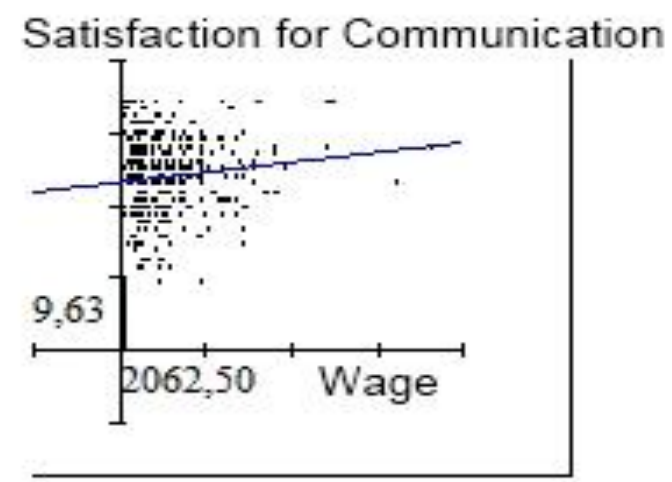

Figure 4: Correlation between Wage and Satisfaction with Communication Process

Note: The figure shows the 423 coordinate points: wages; communication process satisfaction. The dependence is not significant. Right regression equation: Satisfaction process $=0.00 *$ wages +22.60 . Correlation coefficient: +0.11 (wages explains $1.1 \%$ of the communication satisfaction variance). Standard deviation of the regression coefficient: 0.000 . Fisher coefficient: $F=4.89$.

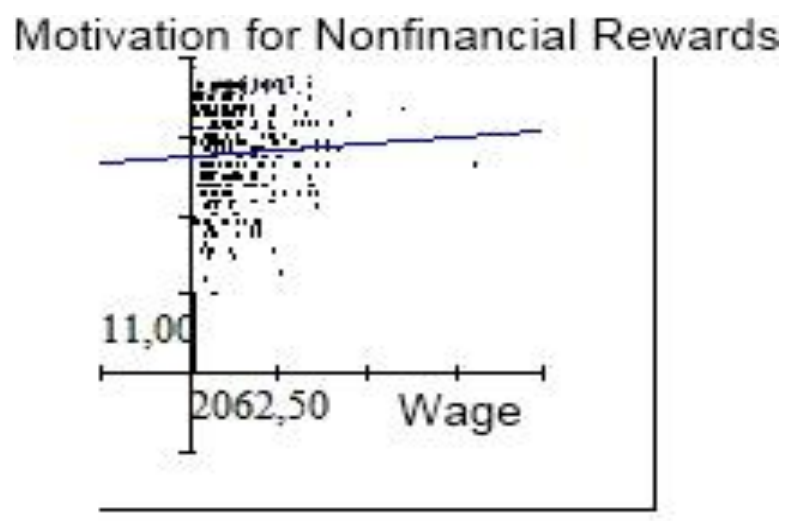

Figure 5: Correlation between Wage and Motivation for Non-financial Rewards

Note: The figure shows the 425 coordinate points: wages; motivation for compensations. Dependence is not significant. Right regression equation: motivation for compensations $=0.00 *$ wages +30.40 . Correlation coefficient: +0.06 (wages explains $0.4 \%$ of compensation motivation variance). Standard deviation of the regression coefficient: 0.000 (very little influence). Fisher coefficient: $\mathrm{F}=1.67$. 


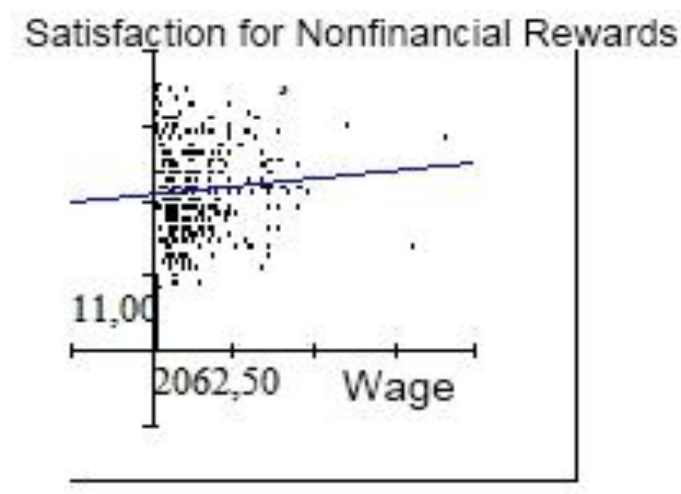

Figure 6: Correlation between Wage and Satisfaction with Non-financial Rewards

Note: The figure shows the 423 coordinate points: wages; compensations of satisfaction. The dependence is not significant. Right regression equation: compensations of satisfaction $=0.00 *$ wages +23.14 . Correlation coefficient: +0.08 (wages explains $0.6 \%$ of the compensation variance). Standard deviation of regression coefficient: 0.000 (very little influence). Fisher coefficient: $\mathrm{F}=$ 2.61 .

The above-mentioned findings provide an answer to the following question: "To what extent do the actual wages relate to the motivation and satisfaction of the wage earners who are considered to present higher motivation than their colleagues in terms of work organization system, communication system, and reward systems?"

The results - all statistically insignificant - show that the levels of wages paid does not influence the motivation and satisfaction of the respondents in terms of all the surveyed set of variables.

Taking into consideration that $56 \%$ of the respondents work in the administrative areas of the surveyed firms, the following specific findings was extracted from them:

- $\quad$ The only company among those surveyed, in which the construct 'motivation for work organization system' presents a significant dependency on real wages, is that which pays the lowest wages.

- In two companies, the employees' satisfaction with the construct 'work organization system' presents significant dependencies on the wages. Precisely, the company, in which the employees express the greatest level of satisfaction, pays the lowest wages. The company in which employees present the lowest level of satisfaction pays wages close to that of the average for all the surveyed companies.

- The only company in which the construct 'motivation for communication system' presents significant dependence on wage is that which pays the lowest wages.

- In two companies, the construct 'satisfaction with communication system' presents significant dependency upon actual wages. Precisely, the company in which the employees express the greatest level of satisfaction with communication system pays the lowest wages and the company in which the employees present the lowest level of satisfaction with communication system pays wages close to that of the average for all surveyed companies.

- $\quad$ The construct 'motivation for non-financial rewards system' shows no statistically significant relationship with the real wage.

- In three companies, employees' satisfaction with 'nonfinancial rewards system' presents significant dependencies on the real wage. The company in which the employees express the greatest level of satisfaction with this construct pays the lowest wages. In two companies in which the employees present a lower level of satisfaction with rewards, the wages of one of them are close to the average and those of the other are the highest verified in the survey.

In summary, one observes that the company that pays the lowest wages to the employees in the administrative area presents a group of wage earners that stands out in terms of motivation and satisfaction in relation to the others. This indicates that motivation and satisfaction do not relate positively with the wages received 
(in other words, relate negatively). However, some may argue that the wage paradigm for employees from this company may be a set of wages paid in the region, not the set of wages of the companies surveyed. Thus, it would be necessary to conduct a survey in the region to verify the wage position of this company within the region. Nevertheless, the results also show that in two companies in which the employees present a lower level of satisfaction with rewards, the wages paid by one of them are close to the average verified in the survey and those paid by the other are the highest.

The results verified from the total sample reinforce the thesis that the wage paid by companies (real salary), as an extrinsic reward, does not influence the motivation and satisfaction with work organization system, communication system, and reward system. In similar vein, Kuvaas (2008) tested the relationship between intrinsic motivation and work performance. The findings suggest that some variables are partly - and others fully - mediated by intrinsic motivation. However, the results are contrary to discoveries communicated by authors such as Eisenberger and Cameron (1996), Gawel, 1997; Harpaz, 1990; Jenica, 2007; and Lindner, 1998.

According to Lawler (2000), "Although money may not be the most important reward for some, it usually is important to most people" (p.76). If this affirmation were to be applicable in any universe, the results of this survey would be different. Therefore, based on the results obtained in this work, some provocative questions are brought forth:

1. Would it be possible to prove that the employees - who work for the company that pays the lowest wages and are the most motivated and satisfied - do not have targets?

2. Would it be possible to prove that they are not motivated by other challenges that exist in achieving their targets; that is, for needs, such as self-esteem, that may be satisfied by achieving objectives, as well as accomplishments they make when they do the best task that they are able to perform?

3. What should one say about the influence of money in the case of the company that pays its employees the highest wages and presents the lowest level of satisfaction with the non-financial rewards they receive?

Lastly, according to Kohn (1993), rewards motivate people to get rewards.

\section{CONCLUSION}

Through cross-references in the total sample, it was verified that the wages paid by the companies do not significantly influence the motivation and satisfaction of the respondents in terms of the surveyed constructs. Therefore, as an answer to the survey question and to the assumption underlying this study, no significant dependencies were found. That is, the actual wages a person receives does not significantly influence her/him to be motivated for, or satisfied with the work organization system, communication system, and reward systems. Therefore, the hypothesis of the influence of the wage on motivation was rejected and the results support the authors that assert the fragility of the influence of extrinsic factors (wage is one of them) on the individual's motivation and satisfaction.

These findings explain the reality of the surveyed companies and cannot be extended to the entire Brazilian corporate universe. However, since the survey was conducted with different types of companies from a variety of business sectors, and supposedly with different organizational cultures, and as all the results clearly pointed out in a single direction (wage does not affect or does not positively influence motivation), one may say that they may be applicable broadly to a certain extent.

Although some researchers state that, there is no longer any need to conduct studies on the origin of motivation - whether intrinsic, or extrinsic - certain previous studies that were mentioned in this work question this statement. That is, several surveys found different results from those that are presented in this paper as well those shown by other researchers such as, Herzberg, Kohn, Latham, and Pinder.

Thus, it is recommended that more surveys along this line are conducted - focusing on distinct motivational profiles of workers - in order to verify clearer tendencies in the other regions of Brazil, as well as around the globe, since knowledge can be renewed and consolidated with the accumulation of evidence. Concerning this subject, it seems that more evidence is necessary. 
This paper offers its contribution on two main premises: 1) a study of the relationship of actual wage to motivation and satisfaction by analyzing a broad range of dependent variables and 2) carrying out the study in quite a few companies along with hundreds of wage earners who were considered as being the most motivated.

\section{AUTHOR INFORMATION}

Eder Paschoal Pinto has carried out a post-doctoral research at the Australian National University and received his doctorate in Business Administration from the School of Business Administration of São Paulo (FGV EAESP), with a thesis research carried out in the U.S. (The George Washington University). He is a professor of Organizational Studies, Marketing and, of Strategy at the Salvador University. Formerly, he served as a Professor at the Catholic University of Paraná (Master of Education) and at the University of Ceará (Master of Business). His research interests are in interdisciplinary themes, including issues in the areas of Education, Labor, Marketing, Organizational Studies and, Strategy. E-mail: eder.pinto@anu.edu.au

\section{REFERENCES}

1. Adams, J. S. (1965), "Inequity in social exchange", in Berkowitz, L. (Ed.), Advances in experimental social psychology, New York, Academic Press, v.2, pp. 233-256.

2. Baard, P.P., Deci, E.L. and Ryan, R.M. (2004), "Intrinsic need satisfaction: a motivational basis of performance and well-being in two work settings", Journal of Applied Social Psychology, 34, pp. 20452068.

3. Bandura, A. (1982), "The assessment and predictive generality of self-percepts of efficacy", Journal of Therapy and Experimental Psychiatry, 13, pp. 195-199.

4. Bandura, A. (1997), Self-efficacy: The exercise of control, New York, Freeman \& Company.

5. Beer, M. and Nohria, N. (2000), Break the code of change. Boston, Harvard Business School Press.

6. Deci, E. L. and Ryan, R. M. (1985), Intrinsic motivation and self-determination in human behavior, New York, Plenum.

7. Deci, E.L. and Ryan, R.M. (2000), "The 'what' and 'why' of goal pursuits: human needs and the selfdetermination of behavior, Psychological Inquiry, 11, pp. 227-268.

8. Eisenberger, Robert and Cameron, Judy (1996), "Detrimental effects of reward: reality or myth?" The American psychologist, Vol. 51 No. 11, 1153-1166.

9. Gawel, J. E. (1997), "Herzberg's theory of motivation and Maslow's hierarchy of needs", Practical Assessment, Research \& Evaluation, Vol. 5 No. 11.

10. Greenberg, J. and Baron, R.A. (2008), Behavior in organizations, 9 Ed, India, Prentice Hall.

11. Harpaz, I. (1990), "The importance of work goals: an international perspective", Journal of International Business Studies, 21, pp. 75-93.

12. Herzberg, F.W. (1968), "One more time, how do you motivate employees?", Harvard Business Review, Jan.-Feb., pp. 53-62.

13. Jenica, P. (2007), "What motivates employees of banking system". Revista Tinerilor Economist Finances Accounting, pp. 29-39, available at http://feaa.ucv.ro/RTE/008-04.pdf, (accessed 13 September 2010).

14. Kanfer, R., Chen, G. and Pritchard, R. (Eds.) (2008). Work motivation: Past, present, and future. NY, Psychology Press [SIOP Frontier Series Volume].

15. Kuvaas, B. (2008) "A test of hypotheses derived from self-determination theory among public sector employees", Employee Relations, Vol. 31 No. 1, pp. 39-56.

16. Kohn, A. (1993), "Why incentive plans cannot work", Harvard Business Review, 71, pp. 54-63.

17. Latham, G. P. and Pinder, C. C. (2005), "Work motivation theory and research at the dawn of the twentyfirst century". Annual Review of Psychology, 56, pp. 485-516.

18. Lawler, E.F. (2000), "Rewarding excellence: pay strategies for the new economy”, San Francisco, CA, Jossey-Bass.

19. Leavitt, H. J., Pondy, L.R. and Boje, D M. (1989), Readings in managerial psychology, Chicago, University of Chicago Press.

20. Lindner, J.R. (1998), "Understanding employee motivation”, Journal of Extension, Vol. 36 No. 3, 1-8.

21. Linz, S.J. (2003), “Job Satisfaction among Russian workers”, International Journal of Manpower, Vol. 24 No. 6, pp. 626-652. 
22. Lovelock, C.H. and Wirtz, J. (2001), Services marketing, 5th Ed., New York, Pearson Prentice Hall.

23. Maslow, A. H. (1943), “A theory of human motivation", Psychological Review, 50, pp. 370-396.

24. McClelland, D.C. (1961), The Achieving Society. Princeton, NJ, Van Nostrand.

25. McClelland, D.C. (1985), Human motivation. Glenview, IL, Scott Foresman.

26. Ohtake, F. and Karato, K. (2005). "Performance-based wage system and motivation to work", available at http://www.esri.go.jp/jp/prj-2004_2005/macro/macro16/08-2-R.pdf (Accessed in 23 August 2010).

27. Roberts, J.A., Hann, Il-Horn and Slaughter, S.A. (2006) "Understanding the motivations, participation, and performance of open source software developers: a longitudinal study of the Apache Projects",

Management Science, Vol. 52 No.7, pp. 984-999.

28. Ryan, R.M. and Deci, E.L. (2000), "Self-determination theory and the facilitation of intrinsic motivation, social development, and well-being", American Psychologist, 55, pp. 68-78.

29. Ryan, R.M., Sheldon, K.M., Kasser, T. and Deci, E.L. (1996), “All goals were not created equal: An organismic perspective on the nature of goals and their regulation", in. Gollwitzer, P. M. e Bargh, J. A. (Eds.), The psychology of action: Linking motivation and cognition to behavior, New York, NY: Guilford, pp. 7-26.

30. Schermerhorn, Jr. (2005), Management, 8th Ed., John Wiley \& Sons.

31. Spitzer, D.R. (1995), Supermotivation: A blueprint for energizing your organization from top to bottom, New York, Amacon.

32. Thomas, K.W. (2009), Intrinsic motivation at work: what really drives employee engagement?, San Francisco, CA, Berrett-Koehler. 
NOTES 